\title{
Cultural and Entertainment Life of the Russian Provincial Town in the Late 19th-Early 20th Century (Based on the Example of the City of Kursk)
}

\author{
Mikhail Yurievich Semenov* and Eugeniy Vladimirovich Dvoretskiy \\ Federal State Autonomous Educational Institution of Higher Professional Education "Belgorod State University", \\ Belgorod, Russian Federation; semenov@bsu.edu.ru
}

\begin{abstract}
The current research results are based on the different historical sources, which contain information about cultural life of Kursk during the period from the end of the 19th to the beginning of the 20th century. The analysis involved historical sources led to a number of assumptions regarding the formation and development of urban culture in the Russian province at the turn of the 19-20th centuries.
\end{abstract}

Keywords: Cultural Periphery, Historical Urbanistics, Russian Province, Urban Culture

\section{Introduction}

Before speaking about the principle item mentioned in the title of the article, we should specify, first of all, the term the Russian province. The notion province is often used in Russian human science not only to nominate cities and regions, which are geographically distant from the metropolitan centers, but also to refer to a particular lifestyle or way of life. It results in a conceptualization of province not only (and not so much) as a geographical periphery, but also as a cultural periphery (particularly at the end of the 19th and the beginning of the 20th centuries). Such conclusion is based on the fact that contemporary Russian human science does not present the holistic (systemic) picture of the Russian province cultural life history of the turn of the 19th and 20th centuries. That is why the first task is to reconstruct the history of the cultural life in Kursk of the named period. So, the object of the study is the cultural life of Russian provincial city of Kursk at the end of the 19th and the beginning of the 20th centuries. The choice of this city is based on its geographical remoteness from metropolitan centers and also on that fact that they are agricultural centers with predominantly peasant population. So these factors allow to characterize Kursk as a typical province (in the geographical, historical and cultural dimensions). To prove this conclusion, it is necessary to reconstruct the history of the cultural life of Kursk at the given period. In order to do this, we study and analyze various historical sources, which contain information about the cultural life of the city. The main problem we face while reconstructing the cultural life history of provincial city is that there was no tradition of cultural events recording (in comparison with economical events, for example) and as a consequence of it we have only some fragmentary information. We study historical sources which appeared during the period of the so called forced industrialization in the Russian Empire. This confines the chronological framework of the research to the end of 1890s of the 19th century, on the one hand and to the beginning of the First World War (1914) on the other. Both of these phenomena have fundamentally changed the social and cultural life of the Russian society (including provincial society).

\footnotetext{
${ }^{*}$ Author for correspondence
} 


\section{Method}

This article is devoted to the description of entertainment and leisure activities, which are understood as an integral part of the cultural life of the city, as the city itself represents the special social and cultural space, "simulating a vacation", understood in cultural studies as vacuous after hours (free) time ${ }^{1}$.

Once in the space of urban culture, cultural and information environment the individual's worldview is gradually changing and transforming its traditional (settled) way of life. The fact is that a special type of thinking that focuses primarily on meeting personal needs, as neighborly relations lose their original meaning, is formed in the very city. A man caught by the city or permanently associated with it, is gradually being captured by the city's culture and entertainment as a part of it.

In a narrow sense, entertainment refers to a certain kind of townspeople's activity, which aims at regular meeting personal needs for obtaining positive emotions in the spare from work time, associated with certain financial costs (for example, the purchase of the entrance ticket to the attraction).

\section{Results and Discussion}

Information about the cultural and entertainment life of the city of Kursk of the late 19th - early 20th century can be found in Kursk periodicals of the late 19th - early 20 th century. This very type of historical sources makes it possible to compile the most complete picture of the daily life of Kursk townspeople with entertainment as a part of it. In addition, articles and essays published in the local press during this period reveal a list of major entertainment events available in Kursk at the turn of the century, as well as their frequency and popularity. In addition to periodicals archival materials have also been used.

The analysis of the studied historical sources has made it possible to distinguish two types of entertainment in Kursk in the period under review:

- Entertainments organized by the residents of the provincial center.

- Entertainments imported in Kursk (in this case, residents were only spectators or consumers).

The first type of entertainment primarily includes folk festivals, which refer to a range of activities aimed at the organization of time of the urban population ${ }^{2,3}$.

Local periodicals of the period under review reported that the venue for folk festivals was one of the central squares of the city - Georgievskaya Square. Also, Kursk press informed about the list of entertainment offers, which were very diverse: “... carrousels and booths [were] on the main backdrop", they were very popular, "chevaliers are prancing on wooden horses, young ladies modestly sit down into the sleigh ..." ${ }^{4}$. Moreover other types of entertainment events were offered - shooting, swings, a brass band, fireworks, "bored of the carousel shooting is available ... got tired of shooting, - you can go to a carousel... here is also a brass band and string band (tweedling somewhere), a violin and a musical box and at night there is a "fantastic" lighting of a Bengal light there"4.

According to Kursk Newspaper festivities were a regular and widespread phenomenon in the cultural life of the city: "It is enough that, even in everyday life [about Georgievskaya Square of the city] hundreds of people are here, but during the holidays their number can be counted to thousands" ${ }^{4}$. Hence it is evident that these types of entertainment were popular, as it was reported in the named publication: riding on the carousel, drinking kvass and eating seeds attracted most "... workmen and maids and just burghers and urban inhabitants" 4 .

Kursk press of the beginning of the 20th century considered all of the above mentioned types of entertainment to be nonsense and deprived of content, explaining their popularity by the low overall culture of the inhabitants of the provincial center, as it was evidenced by the certain behavior of folk festivals visitors "seeds predominate, of course, ... the crackle of their clicking is like a groaning sound heard over the whole area ... secondly after the seeds goes the kvass 4 .

"The local press associated grassroots of these folk festivals with a low level of material well-being of the most part of Kursk population, noting: "And what specific proportionality exists between "panis" and "circenses"... ("bread and circuses"- M.S.) no doubt that increasing quantity of the former progressively increases the quality of the latter"4.

In general, local press spoke of national festivities in a negative way, considering them to be an outdated and even shameful manifestation of the people's (fair) culture, which had nothing to do with urban culture. 
Describing it very simplistically, Kursk newspapers regarded the festivities as a regressive phenomenon, as a manifestation of lack of culture and even barbarism, "Isn't it outrageous in fact to call barbarous such a city as Kursk, with an electric tram rushing along its streets, electric lights lightning it during the night, a city with "hotels", amateur theatricals ... arranged booths and carousels 4 . Limited characteristics of newspapermen of the studied phenomenon was the main reason of misunderstanding of the contradictions of social and cultural life of the city: "Here, posters announcing the concert of Medea Figner (see Appendix) and numerous amateur theatricals ... Figner and roundabouts ..." Lovers of Dramatic Art "and" advanced "swing" were [could be] pasted on Georgievskaya Square".

As can be seen, "noninvolvement into a particular type of life and behavior" and pastimes was interpreted by periodicals of the provincial center exclusively as a manifestation of the signs of non-urban culture ${ }^{5}$. It can be concluded that the festivities were really a massive and popular phenomenon with townspeople, because they were relatively easy to access, they formed a variety and were easy to understand. Moreover, festivities, understood as a part of the traditional, centuries-old fair culture are seen as an essential component of everyday Russian provincial town life in this article.

Along with the folk festivals generated within the urban space of the provincial center one can also include celebrations, organized by the City Government for charitable purposes, into the first type of entertainment.

For example, the report of Kursk policeman contains reporting information about the festivities held in 1891 in favor of the Aleksandrovskiy House of Contempt of the Poor. During the summer of 1891 the City Government organized and held a series of celebrations, on June 7, 14, 21, 30, July 28, August 11, 18 and 25.

From the estimates of expenditure and income, represented to the Governor of Kursk by the chief of police for each of the festivities, you can form an idea about their popularity and availability for the general public, as well as on the variety of the entertainment proposed to people. The entrance fee to the city park, which hosted the celebrations, was low (20 kopecks) (for comparison - a ticket to the concert of popular gypsy romance singer A.D. Vyaltseva cost from 1 ruble 70 kopecks to 6 rubles 20 kopecks). Appealing to the Kursk public were also recreational activities offered by the city government: fireworks, balloons, speech magicians, raffles, performances by artists and musicians ${ }^{6}$. Ticket information indicated the popularity of festivals with Kursk townspeople. Thus, for example, on June 30647 tickets were sold, on July 28 - 432, on August $25-433^{6}$.

Alongside with the folk festivals that had a rather spontaneous nature and were a manifestation of the traditional fair culture, as well as with festivals, initiated by the local government of Kursk, celebrations organized by the Society for Promotion of Primary Education in Kursk Province were held. This public organization also offered leisure festivities, primarily having educational goals and contrasting festivities on Georgievskaya Square. To carry out the festivities for educational purposes in 1903 the District Council let Lazaretny Garden to the Society for free - the oldest public garden in Kursk, now defunct.

From the report of the Company for 1903 we can conclude that festivals were primarily targeted at the poorest segments of the population who, due to low incomes, did not have an opportunity to attend other recreational activities and entertained primitively. Their main goal was to spread cultural activities among the masses instead of traditional ones, which members of the Society interpreted negatively.

"By enabling urban poor people to spend a holiday vacation in a good atmosphere, sober and fun - as it was determined by their organizers - the people's garden ennobles the tastes and needs of its visitors and displaces those rough and often unwholesome entertainments, which, unfortunately, were usually a festive pastime of urban common people ${ }^{7}$

In accordance with the concept of the third branch of the Society, which was responsible for organizing festivals, their program was to consist "mainly of educational entertainment, not excluding from the program, however, entertainment of indifferent nature, such as: dancing, performance for the eyes and so forth"'.

Consistent with the direction indicated by the preparation of festivities, the following entertainment events were offered: theater performances, amateur accordion performances of Topcheev, light painting, balloon and fireworks.

As you can see, the list of proposed entertainment was modest. This fact was also mentioned in the report of the Society, - "one cannot say that the entertainment program was marked by a great variety of entertainment." Eager to attract more public to Lazaretny Garden the Society 
tried to complement the program by the "Zonophone*, Bioscope $^{\star *}$, tricks, juggling, tableaux, procession of the queen of flowers, sports entertainment and so on"7.

In general, we can conclude that the first education festivities organized by the Society for Promotion of Primary Education attracted the attention of Kursk townspeople, as it is evidenced by the data of the Report: "The garden was very popular with the urban common people visiting it during the season, with at least 2000 people on each holiday"'.

In spite of the deficit resulting from the held festivities (4,291 rubles 76 kopecks were spent for the organization and only 3,432 rubles 90 kopecks received), the members of the society believed that even these figures proved the success of the organized festivities: "the first experience of Kursk folk entertainment should convince any prejudiced person in that fact that a need for a reasonable and sober pastime was already a burning point" . However, it is not possible to trace further dynamics of folk festivals, organized by the company for the promotion of primary education, as there is no information about the activities of this kind in the accounting documentation of the social organization of the later period. In addition to the festivities in the Lazaretniy Garden the Society for Promotion of Primary Education also initiated other forms of entertainment, educational activities with the enlightment goals. For example, from 1 to 13 April, 1903 the Society organized the second exhibition of the Public Art, which displayed the works of local artists for the most part (information about the first exhibition was not preserved).

The reporting documentation said that "all the paintings at the exhibition counted to 139 items and, in addition, 7 items of sculptures ... 28 of them were sent by town artists, 89 given by local artists, while the remaining 29 were sent by individuals"

Since the exhibition was public, it offered democratic entrance fees. Kursk townspeople were invited to attend it for the following price: during the Holy Week - 20 kopecks, during Easter week - 5 kopecks; for elementary schools students the exhibition was free.

In accordance with the table of attendance attached to the report, one can conclude that during the first days the exhibition was not popular and this can be associated with the strict fasting during Holy Week, which lasted from 1 to 6 April in 1903 as well as with the high price of tickets.

This cultural event received coverage in the local periodical press, which reported that in addition to the works of local artists paintings by I.K. Aivazovsky Yalta and Bosporus, by J.J. Clover Fog, Baltic Coast and Bathing in the Lake by M.G. Malyshev; Little Sunset, Padun, In Summer, On Dachas etc. ... were presented?.

In general, it can be concluded that the purpose of the art exhibition was reached. Firstly, it gave an opportunity to townspeople to get acquainted with the works of both local artists and the works of major national artists, attaching them to the visual arts. Secondly, we can say that the exhibition was popular with all categories of the urban population. However, it should be noted that the degree of popularity in the different society sets was different. The main goal of organizers was to educate common people. But most of the visitors constituted intelligent public (1,261 people) and students (950 people). The latter had been traditionally the most active participants of the cultural programs of the society. Unintelligent audience was only 747 people. A notable feature of this audience was the gender selectivity of the consumers of urban culture: the number of unintelligent male visitors was almost the same as in the other categories. Concerning women, they accounted for about half of the educated public and students and only a little more than a quarter from the unintelligent public.

Among the entertainment, imported in the city of Kursk in 19th - 20th centuries, were the concerts and musical evenings with only professional artists staring. It is worth noting that the most part of such entertainment were the performances of native and foreign artists who were nationwide and even European-wide famous. As can be seen from the notes of Kursk press, observing closely the musical life of the city, that almost all of the genres of musical art, popular in the late 19th - early 20th century were available to Kursk townspeople.

At the beginning of the last century the circus stood in competition to the cinema in the provincial center. According to the outset of the proposed typology of entertainment it can refer to imported recreational activities, as during the period under review Kursk had not yet had its own place with a circus arena. However, despite this fact, best of circus arts, due to touring groups and artists of the circus genre were available to Kursk townspeople, as it is evidenced by a number of publications in Kursk periodicals ${ }^{10-24}$.

The first notes about a tour of the circus group in Kursk, written in Kursk Newspaper refer to 1901. From the small note published in the named periodical, one can conclude that the touring circus was popular with Kursk townspeople, since it stayed for a long time in Kursk and an extension 
of its tour was anticipated. Consequently, the circus was popular and had a material success, "Slavic circus giving performances for two months in Kursk, assumes to stay in Kursk for the winter ...."25.

In 1911 the world-famous horse coach Zhizhetto Truzzi visited the provincial center. According to local press reports, he had success with Kursk audience: "On the circus arena Truzzi, greeted with loud applause, showed a lot of new tricks ... [after the performance] there was no end to applause and beneficiary calls of Truzzi"26.

Particular attention of Kursk press was paid to the arrival by A. D. Goretz to the provincial center (from 15 April to the end of May) in 1913 and the number of performances of famous Russian and foreign artists of various circus genres, who toured in Kursk in the same year ${ }^{10,16,18-20,23,27}$. Residents of Kursk had the opportunity to go to circus regularly and meet nearly all genres of circus art, often performed by all-Russian or European famous artists.

Thus, touring groups gave the residents of Kursk the opportunity to meet almost all kinds of acrobatics, as it was written in Kursk press in details ${ }^{10,16,18-20,23,27}$.

The attention of Kursk periodicals was also drawn to the female athlete Marina Lurs, the member of A. D. Goretz touring group and her performances. She was called "the world's only lady-athlete, perfectly accomplishing her athletic performances with weights and a live weight and not conceding first-class male athletes" 10 .

Mastery bike and roller performances were shown at the beginning of August 1913 - "Acrobats on rollers, Five Danels and cyclists Maelstrom"20,21.

Kursk press which observed the tours of circus artists in the provincial center in details, paid attention to the performances of national and foreign artists working in the genre of juggling, 15,19.27,28.

So, among the artists of the circus group by A. D. Goretz were "Mr. Tokashima, who showed remarkable agility, ease and speed in juggling" and "Mr. Kankovskie, who showed us the highest level of all skills juggling with all kinds of objects ... ${ }^{\text {" } 27,28}$.

Illusion as a separate, specific genre of circus arts was also presented in Kursk in summer 1913. Particular attention of Kursk Periodicals was paid to the benefit of P.P. Nikolayev, on April 25, who showed "an interesting performance, called The Captain of the Immortal Regiment ... Mr. Nikolaev gave a gun loaded with buckshot to one of the spectators, who fired (12 steps away) ... Mr. Nikolaev was left unharmed"28. In August of that year"... The Queen of the Illusion Ms. Frankario ..." also toured in Kursk, however, Kursk press did not pay much attention to her performances ${ }^{19,20}$.

The circus by A. D. Goretz showed also the performances of animals relating directly to two genres equestrian and circus training: the first was presented by the performances of m-lle Dora Vasilyamsom Mr. Ivanov, $\mathrm{m}$-lle Flora and $\mathrm{m}$-lle Martynova ${ }^{10,28}$. The second was presented to the performance of $\mathrm{m}$-lleValdos ${ }^{10}$.

The performances of pop genre were characterized by variety and originality, this fact is evidenced by a number of publications in Kursk media which observed the performances of humorists, readers, singers of satirical songs and ventriloquists. Artists of the named genre performed in Kursk during the summer season of $1913^{13,16,20,22,23 \text {. }}$

Along with the representatives of the well-known native pop genre Kursk artists were the touring world famous foreigners: ventriloquists Pierre Dudo, Mr. Alfred F. Christensen; ${ }^{22,28}$ impersonator - Fred Marion ${ }^{16,17,19}$.

A tour of the artist of the original genre, the famous counter in the mind Arrago can be treated as a special event; he had begun his theatrical career in 1909 in Brussels and visited Kursk in October, 1913. The Kursk Newspaper described his phenomenal abilities as follows: "You ask Arrago a question - what day of the week I was born, on January 26, 1876. He immediately replies - that was on Monday"29.

Also local periodicals reviewed performances of artists-eccentrics-American Willie Cornelius performing his original scene on July 24, 1913 - "with the help of chalk and skillful hands of Cornelius furniture, paintings, clocks and many other items on a black background are starting to come to life, the potted flower begins to grow, clocks are set in motion, swinging the pendulum" and native eccentric Pashchenko, who toured in Kursk in early August ${ }^{19,20}$.

Tours of all these circus troupes and circus genre artists were constantly popular with the residents of the provincial center ${ }^{10}$. Obviously, one reason why so much attention of the Kursk public was paid to the named troupe was the conditions created by its authorities. Firstly, as it was noted by the local press, "the circus is big, there is plenty of air and light ... there", moreover the use of new material for covering the dome allowed performing even in bad weather: "On April 15 during the heavy rain it was 
dry in the circus due to the American waterproof canvas". Such organization of the situation, according to Kursk periodicals let the circus keep doing brilliant things, despite the bad weather all the time..." ${ }^{10,28}$.

Secondly, the important factor was the material one: "The public gets a lot of fun at an affordable price"10,27.

\section{Conclusion}

As can be seen, despite the absence of its own circus arena in Kursk, in the early 20th century attending circus was one of the most common and popular form of entertainment with the residents of the provincial center. The frequency of performances of circus genre artists, on the one hand, as well as regular attendance of the organized performances by the city residents, on the other hand, prove that circus was one of the most common and popular types of urban entertainment in the provincial town of the early 20th century. It is confirmed also by the fact that successive circus bands and circus genre artists toured all year round and their performances were regular, varied, accessible, popular, causing positive emotions of the audience and attracted a significant number of residents.

\section{Acknowledgments}

This research was executed with the financial support from the Ministry of Education and Science of the Russian Federation. The project theme is "Cultural and educational activity as a phenomenon in the cultural life of the Russian city in the late 19th - early 20th century". A unique identifier of the applied research is 327.

\section{References}

1. Khrenov NA. Pictures of the world and images of the city. (The Psychological Aspects of Education and Subcultures and their Impact on the Artistic Culture of the City). In City and Art. Actors of Socio-Cultural Dialogue. Moscow; 1996; 32 .

2. Artsizbasheva TN. Love and get to know your Kursk Region (Teaching Aid). Kursk; 2007.

3. Historical and cultural regional studies: Yesterday, today and tomorrow. Materials of the First Scientific and Practical Regional Conference. Kursk, Russian Federation: Kursk University; 1999 May 24-25.

4. Panem et circenses! In The Kursk Newspaper. Kursk. 1902; 44:3
5. Lotman Y. Selected articles. Tallinn. 1993; 3:326

6. Reports of Kursk Chief of the Police and District Police officer on the Held Amateur Performances and Concerts for Charitable Purposes, Receipts and Records of the Receipt and Expenditure of Funds. National Archive of Kursk Region. F.1. Op. 1. 343: 104, 128, 149.

7. Festivities in Lazaretny Garden. Report of the Society for Promotion of Primary Education in Kursk Province. Kursk. 1904; 32-4.

8. About the second public art exhibition of paintings from 1 to 13 April 1903. In Report of Society for Promotion of Primary Education of Kursk Province. Kursk.

9. Chronicle. The Kursk Newspaper. 1903; 74:1.

10. The Opening of the Circus by Goretz AD. The Kursk Newspaper. 1913; 36:2-3.

11. T\&M. Theater and Music. Our Gardens and Summer Entertainment. Kursk Newspaper. 1913; 38:2.

12. T\&M. Theater and Music. Circus by Goretz AD. The Kursk Newspaper. 1913; 40: 2- 4 .

13. T\&M. Theater and Music. Circus by Goretz AD. The Kursk Newspaper. 1913; 43:4.

14. T\&M. Theater and Music. In Circus by Goretz AD. The Kursk Newspaper. 1913; 45:3.

15. T\&M. Theater and Music. The Kursk Newspaper. 1913; 60:2.

16. T T\&M. Theater and Music. The Kursk Newspaper. 1913; 63:3-4.

17. T\&M. Theater and Music. The Kursk Newspaper. 1913; 65:2-4.

18. T\&M. Theater and Music. The Garden of the Commercial Meeting. The Kursk Newspaper. 1913; 66:2.

19. T\&M. Theater and Music. The Garden of the Merchants' Meeting. The Kursk Newspaper. 1913; 68:1-2.

20. T\&M. Theater and Music. The Kursk Newspaper. 1913; 69:1-4.

21. T\&M. Theater and Music. The Kursk Newspaper. 1913; 71:2-3.

22. The Garden of the Commercial Meeting. The Kursk Newspaper. 1913; 74:1-2.

23. The Garden of the Commercial Meeting. The Kursk Newspaper. 1913; 77:2-4.

24. T\&M. Theater and Music. Kursk Commercial Meeting. Arrago Touring. The Kursk Newspaper. 1913; 93:2.

25. To the Tenth Anniversary of the Kursk Musical Circle. The Kursk Newspaper. 1913; 349:2.

26. Circus (the Zh.A. Truzzi Special). The Kursk Newspaper. 1913; 46:3.

27. T\&M. Theater and Music. In Circus by Goretz AD. The Kursk Newspaper. 1913; 45: 3-4.

28. T\&M. Theater and Music. Circus by Goretz AD. The Kursk Newspaper. 1913; 40:2.

29. T\&M. Theater and Music. Arrago's Touring. The Kursk Newspaper. 1913; 93:2.

30. Ilyin Z. Kursk Region. Culture and Cultural and Historical. Kursk. 2002; 15. 